\title{
Diversidade genética entre híbridos de laranja-doce e tangor 'Murcott' avaliada por fAFLP e RAPD
}

\author{
Marinês Bastianel(1) Antonio Carlos de Oliveira $^{(2)}$, Mariângela Cristofani(1) e Marcos Antônio Machado ${ }^{(1)}$
}

\begin{abstract}
(1)Instituto Agronômico, Centro APTA Citros "Sylvio Moreira", Caixa Postal 4, CEP 13490-970 Cordeirópolis, SP E-mail: mbastianel@centrodecitricultura.br (2)Universidade Estadual do Sudoeste da Bahia, Dep. de Ciências Naturais, Caixa Postal 95, CEP 45083-900 Vitória da Conquista, BA. E-mail: ancaol1@yahoo.com.br
\end{abstract}

Resumo - O objetivo deste trabalho foi avaliar a diversidade genética em uma população de 148 híbridos de tangor 'Murcott' (Citrus reticulata Blanco x C. sinensis L. Osbeck) e laranja 'Pêra' (C. sinensis L. Osbeck) obtidos por polinização controlada, pelo uso de marcadores fAFLP e RAPD. Marcadores polimórficos (416 marcadores fAFLP e 33 RAPD) foram utilizados para avaliar a similaridade genética entre os híbridos, calculada com o coeficiente Jaccard pelo método UPGMA. A consistência de cada agrupamento foi determinada pelo programa BOOD. Houve alta similaridade genética entre os parentais. A laranja 'Pêra' apresentou maior número (132) de loci em heterozigose em relação ao tangor 'Murcott' (105), corroborando a teoria de origem híbrida para a laranja-doce. Observaram-se dois grupos distintos de plantas, e um deles abrangeu $80 \%$ dos híbridos com maior similaridade com a laranja 'Pêra'. A análise bootstrap não revelou consistência estatística entre esses grupos. Marcadores fAFLP são mais eficientes na avaliação do polimorfismo, sendo indicados para seleção de indivíduos híbridos mais próximos a um dos parentais.

Termos para indexação: citros, marcadores moleculares, similaridade genética.

\section{Genetic diversity among hybrids of sweet orange and 'Murcott' tangor evaluated by fAFLP and RAPD markers}

\begin{abstract}
The objective of this work was to evaluate the genetic diversity in a population of 148 hybrids of 'Murcott' tangor (Citrus reticulata Blanco x C. sinensis L. Osbeck) and 'Pêra' sweet orange (C. sinensis L. Osbeck), obtained by controlled polination, using fAFLP and RAPD markers. Polymorphic markers (416 fAFLP and 33 RAPD markers) were used to evaluate genetic similarity among the hybrids, calculated by the coefficient of Jaccard, using the UPGMA method. The consistency of each group was determined by software BOOD. There was high genetic similarity within the parents. 'Pêra' sweet orange had a higher number of loci in heterozygosis (132) compared to 'Murcott' tangor (105), supporting the theory of hybrid origin for sweet oranges. Two distinct groups of plants were observed: one group had $80 \%$ of the hybrids that displayed higher genetic similarity with 'Pêra' sweet orange. The bootstrap analysis did not show consistence between the groups. The fAFLP markers are more efficient to obtain polymorphism than RAPDs and are more suitable to select hybrids closer to the parents.
\end{abstract}

Index terms: citrus, molecular markers, genetic similarity.

\section{Introdução}

A citricultura constitui-se em uma das mais importantes cadeias produtivas do Brasil, gerando mais de 1,5 bilhões de dólares por ano (Neves \& Val, 2003), destacando-se nos setores econômico e social. Por se tratar de uma citricultura basicamente voltada para a indústria de processamento de suco para exportação, que responde por mais de $80 \%$ da demanda total da produção (Neves \& Val, 2003), as laranjas-doces (Citrus sinensis L. Osb.) são as variedades mais plantadas e, den- tro deste grupo, destacam-se as laranjas 'Pêra' (40\%), 'Valência' (26\%) e 'Natal’ (23\%) (Dados..., 2001).

A laranja 'Pêra' é bem adaptada às condições climáticas das principais regiões produtoras do Estado de São Paulo; entretanto, é altamente suscetível à clorose variegada dos citros (CVC) (Machado et al., 1993) e à leprose (Bastianel et al., 2004), doenças que afetam a citricultura brasileira. Esforços vêm sendo realizados a fim de selecionar novas variedades de laranja-doce, que apresentem interesse comercial e maior tolerância a doenças (Cristofani et al., 2001). 
Entretanto, a baixa variabilidade genética entre variedades de laranja-doce, demonstrada por recentes estudos moleculares (Federici et al., 1998), e a ausência de variedades mais tolerantes às principais doenças, que afetam a citricultura brasileira, fazem com que fontes de variabilidade genética para incorporação de resistência recaia em outras espécies de citros, tais como as tangerinas e seus híbridos, sabidamente resistentes à CVC e à leprose.

$\mathrm{O}$ tangor 'Murcott' (C. reticulata Blanco $\mathrm{x}$ C. sinensis L. Osbeck), um híbrido natural de laranjadoce e tangerina, é uma variedade comercial no Brasil para consumo in natura e, embora em menor escala, para a indústria de suco (Figueiredo, 1991). Uma das mais importantes características desse híbrido é sua maior tolerância a doenças que afetam os pomares brasileiros, como a CVC (Machado et al., 1993; Oliveira, 2003) e a leprose (Bastianel et al., 2004), o que o torna importante fonte genética para programas de melhoramento de laranjas-doces.

Por serem plantas heterozigotas, gerações $F_{1}$ obtidas de cruzamentos dirigidos em citros apresentam, normalmente, alta taxa de segregação genética. Marcadores moleculares possibilitam a avaliação da similaridade genética entre genótipos nos primeiros estágios de desenvolvimento, e são vantajosos para esse tipo de estudo em plantas perenes, como os citros (Nicolosi et al., 2000). Em cruzamentos dirigidos de citros, informações sobre as relações genéticas entre os híbridos podem orientar a seleção de materiais promissores e o entendimento da herança de diversos caracteres de interesse, e são fundamentais para o melhoramento (Bastianel et al., 1998; Oliveira et al., 2002a).

Em citros, marcadores RAPD (Random Amplified Polymorphic DNA) têm sido utilizados em estudos de diversidade genética (Machado et al., 1995; Bastianel et al., 1998; Nicolosi et al., 2000; Oliveira et al., 2002a; Andrade et al., 2004). Marcadores AFLP (Amplified Fragment Lenght Polymorphism), por sua vez, são considerados mais eficientes que RFLP (Restriction Fragment Lenght Polymorphism), RAPD e SSR (Single Sequence Repeat), pela sua alta reprodutibilidade e elevada taxa multiplex, ou seja, número de marcadores simultaneamente analisados em um mesmo gel, e vêm sendo utilizados para análise de diversidade genética em muitas espécies vegetais (Pejic et al., 1998). Em citros, a utilização de marcadores AFLP é recente e poucos trabalhos utilizando essa categoria de marcadores são relatados. AFLP foram empregados com sucesso na construção de mapas genéticos (Simone et al., 1998; Oliveira, 2003) e na caracterização de híbridos somáticos (Guo et al., 2002).

O objetivo deste trabalho foi avaliar a diversidade genética entre híbridos de tangor 'Murcott' e laranja 'Pêra', pelo uso de marcadores RAPD e fAFLP.

\section{Material e Métodos}

Foram utilizados 148 híbridos de tangor 'Murcott' (parental feminino) e laranja 'Pêra' (parental masculino), previamente selecionados por genotipagem morfométrica e molecular (Oliveira et al., 2002b). O DNA genômico total foi isolado de folhas frescas de acordo com Machado et al. (1995). A concentração e a qualidade das amostras de DNA foram determinadas por visualização sob luz ultravioleta em gel de agarose $(0,8 \%)$ com brometo de etídio $\left(0,5 \mathrm{ng} \mathrm{mL}^{-1}\right)$, e com diluição serial de $\lambda$-DNA (250 a $50 \mathrm{ng} \mathrm{mL}^{-1}$ ) (Sambrook et al., 1989). Alíquotas de cada amostra de DNA foram diluídas a 5 e $100 \mathrm{ng} \mu \mathrm{L}^{-1}$ e armazenadas a $-20^{\circ} \mathrm{C}$, para posterior utilização na geração de marcadores RAPD e fAFLP, respectivamente.

As reações de RAPD foram preparadas conforme descrito por Machado et al. (1995), utilizando-se 13 oligonucleotídeos iniciadores randômicos (OPB13, OPC08, OPE10, OPE17, OPY05, OPY13, OPAB04, OPAB18, OPAF04, OPAF06, OPAF12, OPAT07, OPAT13) (Operon Technologies, Califórnia, USA). Os produtos de reação foram visualizados sob luz ultravioleta em gel de agarose $(1,4 \%)$, corado com 0,5 ng mL ${ }^{-1}$ de brometo de etídio (Sambrook et al., 1989).

Os marcadores AFLP foram gerados utilizando-se o AFLP Plant Mapping Kit - System I com iniciadores marcados com fluoróforos específicos (fAFLP) para o seqüenciador automático ABI Prism 377 (Applied Biosystems), conforme especificações do fabricante, com modificações descritas por Oliveira (2003). Aproximadamente $1 \mu \mathrm{g}$ de cada amostra de DNA foi digerida com as enzimas EcoRI (5U) e MseI (1U) (Gibco) a $37^{\circ} \mathrm{C}$ por 4 horas e estocadas a $-20^{\circ} \mathrm{C}$. Adaptadores EcoRI e MseI foram ligados a alíquotas de DNA e digeridos com T4 DNA ligase (Gibco). As etapas de pré-amplificação, amplificação seletiva e eletroforese seguiram a descrição de Oliveira (2003). Os dados de fAFLP foram coletados e armazenados pelo programa ABI Prism Collection, conforme instruções do fabricante e analisados pelos programas GeneScan, ver- 
são 2.0, e Genotyper, versão 2.5 (Applied Biosystems). A fim de evitar erros decorrentes da automatização da análise dos géis pelo programa Genotyper como, por exemplo, a ausência de determinado fragmento decorrente da não amplificação, a classificação binária (presença/ausência) gerada pelo aplicativo foi visualmente validada, confirmando-se os picos obtidos na corrida eletroforética para cada combinação de iniciadores.

O grau de similaridade entre os genótipos foi estimado por meio da presença ou ausência dos marcadores fAFLP e RAPD nos parentais e sua segregação nos híbridos. Marcadores monomórficos para a progênie não foram considerados na análise, conforme Oliveira et al. (2002a). Cada banda foi considerada um único locus genético, não levando em consideração possível alelismo entre diferentes tipos de AFLP, conforme utilizado por Meyer et al. (2004). A heterozigosidade dos parentais foi comparada pelo somatório do número de bandas presentes nos parentais que se segregavam dentro da população de híbridos (Barbosa Neto et al., 1996). A construção do dendrograma com relações de similaridade entre os indivíduos foi realizada com uso do NTSYS-PC, versão 2.0 (Rohlf, 1997). A matriz de similaridade foi gerada usando o coeficiente Jaccard, e o dendrograma construído pelo método UPGMA (Unweighted Pair Group Method with Arithmetic Averege) (Sneath \& Sokal, 1973). A análise bootstrap de cada agrupamento foi determinada por meio do aplicativo BOOD (Coelho, 2000).

\section{Resultados e Discussão}

Das 64 combinações de oligonucleotídeos iniciadores utilizadas na análise fAFLP, somente 59 produziram produtos de amplificação com resolução suficiente. Foram gerados 416 fAFLP com tamanho entre 50 e 500 pb. A análise de segregação desses fAFLP na progênie resultou na identificação de 89 marcadores fAFLP heterozigotos em tangor 'Murcott' (21,4\% do total), 122 em laranja 'Pêra' (29,2\%) e 205 em ambos parentais (49,4\%). Os 15 iniciadores randômicos (RAPD) geraram um total de 33 bandas polimórficas, sendo 16 heterozigotas no tangor 'Murcott' (48,5\%), 11 na laranja 'Pêra' (33,3\%) e seis (18,2\%) em ambos parentais.

Conforme Saliba-Colombani et al. (2000), o número de loci polimórficos detectados em uma progênie é proporcional à distância genética entre seus parentais. O fato de terem sido detectados 50,6\% de loci polimórficos entre os parentais evidencia a existência de distância genética de magnitude intermediária entre eles. Esses resultados podem ser explicados, tendo em vista que o tangor 'Murcott' é um híbrido de laranjadoce. Além do mais, é provável que a laranja-doce tenha também origem híbrida, com uma tangerina como um dos seus parentais (Barret \& Rhodes, 1976).

$\mathrm{O}$ alto grau de heterozigosidade de híbridos de laranja-doce justifica a hipótese de origem híbrida desse táxon (Federici et al., 1998). Essa hipótese é reforçada neste trabalho, uma vez que o número de loci (fAFLP e RAPD) em heterozigose detectado em 'Pêra' foi superior (132) ao verificado para tangor 'Murcott' (105).

O número de fAFLP gerado por combinação de iniciadores foi de, em média, 4,9 para tangor 'Murcott' e 5,5 para laranja 'Pêra', significativamente inferior ao obtido por Guo et al. (2002) em Poncirus trifoliata (40) e tangerina (25) (Citrus reticulata Blanco cv. Red). Possivelmente, esse número de AFLP deve-se à distância genética maior entre essas espécies. Maior similaridade genética entre as variedades de laranja doce e tangor 'Murcott' do que entre Poncirus trifoliata e C. reticulata foi demonstrada, recentemente, por Nicolosi et al. (2000), em estudos de filogenia dos citros com base em marcadores moleculares RAPD, SCAR e cpDNA. Entretanto, apesar do reduzido número de fAFLP em relação ao total de fragmentos gerados, a eficiência desse marcador (número médio de loci polimórficos por combinação de iniciadores) foi superior à observada com marcadores RAPD (1,46 e 1,13 locus polimórfico por iniciador, para tangor 'Murcott' e laranja 'Pêra', respectivamente) e, de modo similar, superior ao polimorfismo verificado em outros estudos de diversidade genética em gerações $\mathrm{F}_{1}$ de citros avaliados por RAPD. Bastianel et al. (1998) e Oliveira et al. (2002a) encontraram média de três loci polimórficos por iniciador RAPD, analisando híbridos de tangerinas ‘Montenegrina' $\mathrm{x}$ 'King' e laranja 'Pêra' $\mathrm{x}$ tangerina 'Cravo', respectivamente. A maior capacidade de gerar polimorfismo dos marcadores fAFLP, em comparação com marcadores RAPD, os credenciam para estudos de diversidade genética em citros.

O coeficiente de Jaccard tem sido utilizado nos estudos de diversidade genética em plantas (Jakše et al., 2001; Oliveira et al., 2002a). Em milho, a comparação de diferentes coeficientes de similaridade demonstrou que o tipo de marcador molecular utilizado em análises de similaridade pode causar alterações nas análises e 
interpretações dos resultados (Meyer et al., 2004). Em estudos de diversidade com dados gerados por marcadores dominantes, como RAPD e AFLP, coeficientes que não consideram as ausências de fragmentos como evidências de homologia, tais como Jaccard,
Sorensen-Dice, Anderberg e Ochiai's, são os mais indicados (Meyer et al., 2004).

$\mathrm{O}$ agrupamento do coeficiente Jaccard pelo método UPGMA resultou em um dendrograma (Figura 1), em que os híbridos foram separados em dois

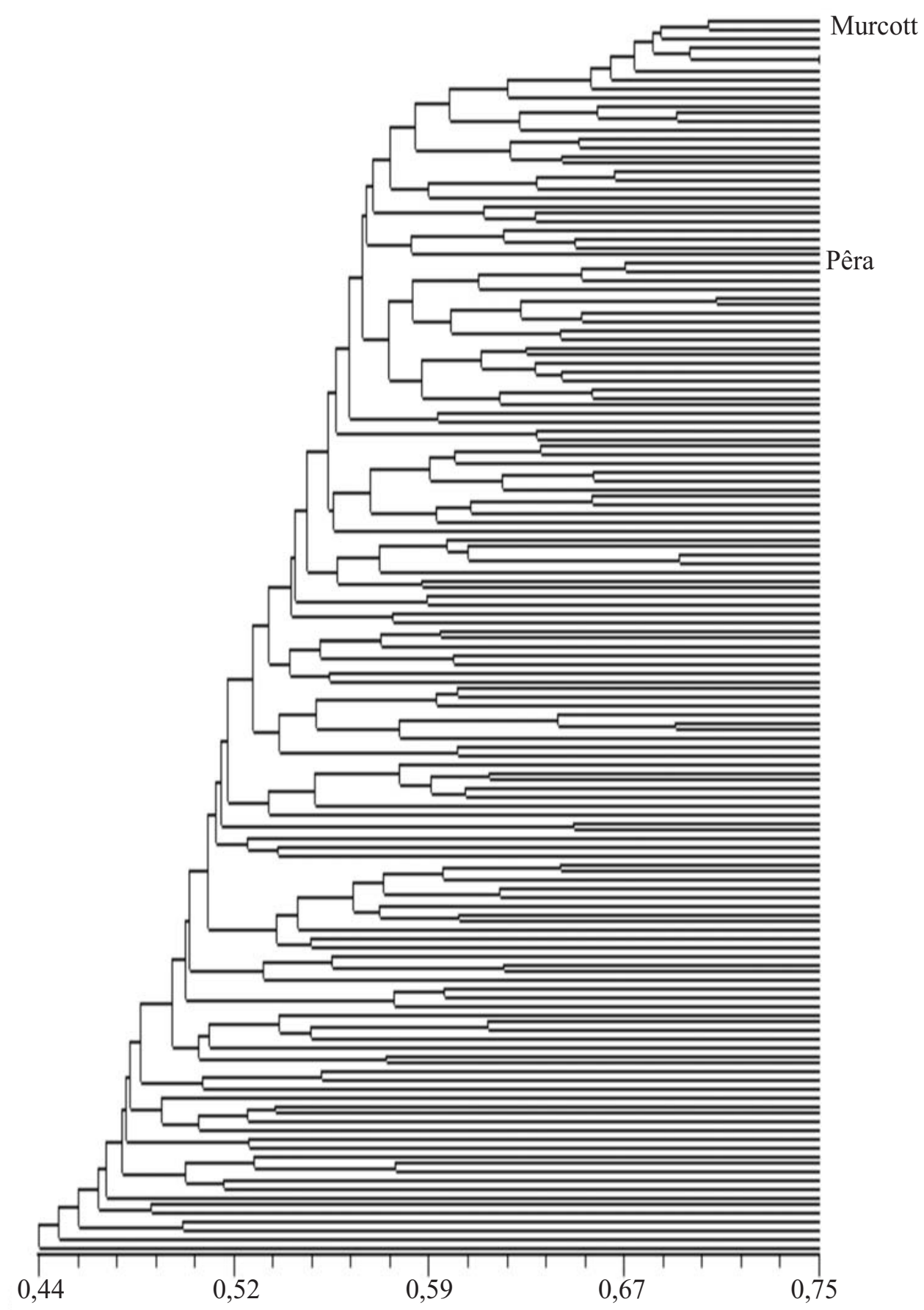

Figura 1. Dendrograma baseado no coeficiente Jaccard entre híbridos de tangor 'Murcott' e laranja 'Pêra'. As posições relativas dos parentais estão destacadas. As demais linhas representam, cada uma, um indivíduo híbrido. No eixo x, encontram-se os valores de similaridade. 
grupos, um contendo cerca de $80 \%$ dos indivíduos com maior similaridade genética com laranja 'Pêra', e outro com os 27 híbridos restantes (20\%) com maior similaridade com tangor 'Murcott'. Essa maior proporção de híbridos similares ao parental masculino laranja 'Pêra' está de acordo com a origem do tangor 'Murcott', um híbrido de laranja-doce. Assim, uma progênie gerada a partir de fecundação cruzada entre tangor 'Murcott' e laranja 'Pêra' seria um tipo de retrocruzamento e, portanto, os genomas desses híbridos apresentarão maior contribuição porcentual de laranja 'Pêra'.

Como pode ser observado no dendrograma (Figura 1), houve a formação de pequenos subgrupos entre os híbridos. Entretanto, a análise bootstrap não revelou consistência estatística entre esses grupos. Conforme Oliveira et al. (2002a), a não-formação de grupos estatisticamente significativos pode ser decorrente da constituição genética dos híbridos que, neste trabalho, teria sido originada pela segregação independente dos marcadores RADP e fAFLP, sendo quebrado o efeito da ligação, de acordo com o tamanho amostral da população segregante (148) e com o número de marcadores utilizado (448). Pejic et al. (1998), analisando a similaridade genética em 33 linhagens de milho com marcadores RAPD, SSR e AFLP, observaram que 150 marcadores foram suficientes para estimar a similaridade genética, e que o acréscimo no número de marcadores não aumentou a precisão dos resultados.

Marcadores moleculares são considerados excelentes ferramentas para avaliação da diversidade genética em muitas espécies de plantas (Garcia et al., 1998). No melhoramento de espécies perenes de longo ciclo vegetativo como os citros, essa ferramenta pode direcionar a seleção precoce de híbridos mais próximo ao parental de interesse. Marcadores fAFLP mostraram-se mais eficientes do que RAPD, na construção de dendrogramas de similaridade genética em híbridos de citros. Estudos complementares poderão dar subsídios aos trabalhos de seleção dos híbridos de acordo com maiores ou menores similaridades com parentais próximos geneticamente.

\section{Conclusões}

1. Existe alta similaridade genética entre as variedades tangor 'Murcott' e laranja 'Pêra'.
2. A laranja 'Pêra' apresenta maior heterozigosidade que o tangor 'Murcott'.

3. Marcadores fAFLP são eficientes na construção de agrupamentos de híbridos e no estudo de similaridade genética desses híbridos com seus parentais.

\section{Agradecimentos}

À Fapesp, pela bolsa de Doutorado; ao Instituto do Milênio/CNPq, pelo suporte financeiro; à Universidade Federal de Goiás e ao Dr. Alexandre Siqueira Guedes Coelho, pela cessão do aplicativo BOOD.

\section{Referências}

ANDRADE-RODRÍGUEZ, M.; VILLEGAS-MONTER, A.; CARRILLO-CASTAÑEDA, G.; GARCÍA-VELÁZQUEZ, A. Polyembriony and identification of Volkamerian lemon zygotic and nucellar seedlings using RAPD. Pesquisa Agropecuária Brasileira, v.39, p.551-559, 2004.

BARBOSA NETO, J.F.; SORRELLS, M.E.; CISAR, G. Prediction of heterosis in wheat using coefficient of parentage and RFLP-based estimates of genetic relationship. Genome, v.39, p.1142-1149, 1996.

BARRETT, H.C.; RHODES, A.M. A numerical taxonomic study of affinity relationships in cultivated Citrus and its close relatives. Systematic Botany, v.1, p.105-136, 1976.

BASTIANEL, M.; FREITAS-ASTÚA, J.; RODRIGUES, V.; ANTONIOLI-LUIZON, R.; ARRIVABEM, F.; MACHADO, M.A. Resposta do tangor 'Murcott' à inoculação do vírus da leprose dos citros em campo e em casa de vegetação. Laranja, v.25, p.337-348, 2004.

BASTIANEL, M.; SCHWARZ, S.F.; COLETTA FILHO, H.D.; LIN, L.L.; MACHADO, M.; KOLLER, O.C. Identification of zygotic and nucellar tangerine seedlings (Citrus spp.) using RAPD. Genetics and Molecular Biology, v.21, p.123-127, 1998.

COELHO, A.S.G. BOOD: avaliação de dendrogramas baseados em estimativas de distâncias/similaridades genéticas através do procedimento de bootstrap. Goiânia: UFG, 2000. 1 disquete.

CRISTOFANI, M.; NOVELLI, V.M.; OLIVEIRA, A.C.; OTAVIANO, A.R.; SOUZA, A.A.; MACHADO, M.A. Identificação de híbridos interespecíficos em citros utilizando marcadores RAPD e SSR. Laranja, v.22, p.231-241, 2001.

DADOS: a polêmica dos números citrícolas. Informativo Centro de Citricultura, v.68, p.3, 2001.

FEDERICI, C.T.; FANG, D.Q.; SCORA, R.W.; ROOSE, M.L. Phylogenetic relationships within the genus Citrus (Rutaceae) and related genera as revealed by RFLP and RAPD analysis. Theoretical and Applied Genetics, v.96, p.812-822, 1998.

FIGUEIREDO, J.O. de. Variedades copa de valor comercial. In: RODRIGUEZ, O.; VIÉGAS, F.; POMPEU JUNIOR, J.; AMARO, A.A. (Ed.). Citricultura brasileira. Campinas: Fundação Cargil, 1991. v.1, p.228-264. 
GARCIA, E.; JAMILENA, M.; ALVAREZ, J.I.; ARNEDO, T.; OLIVER, J.L.; LOZANO, R. Genetic relationships among melon breeding lines revealed by RAPD markers and agronomic traits. Theoretical and Applied Genetics, v.96, p.878-885, 1998.

GUO, W.W.; CHENG, Y.J.; DENG X.X. Regeneration and molecular characterization of intergeneric somatic hybrids between Citrus reticulata and Poncirus trifoliata. Plant Cell Reports, v.20, p.829834, 2002.

JAKŠE, J.; KINDLHOFER, K.; JAVORNIK, B. Assessment of genetic variation and differentiation of hop genotypes by microsatellite and AFLP markers. Genome, v.44, p.773-782, 2001.

MACHADO, M.A.; COLETTA FILHO, H.D.; TARGON, M.L.P.N.; POMPEU JUNIOR, J. Genetic relationship of Mediterranean mandarins (Citrus deliciosa Tenore) using RAPD markers. Euphytica, v.92, p.321-326, 1995.

MACHADO, M.A.; SILVÉRIO, J.L.; BAPTISTA, C.R.; LARANJEIRA, F.F.; BERETTA, M.J.G. Avaliação de transmissão e seleção de variedades à clorose variegada dos citros. Laranja, v.14, p.167-176, 1993.

MEYER, A. da S.; GARCIA, A.A.F.; SOUZA, A.P. de; SOUZA JUNIOR, C.L. de. Comparison of similarity coefficients used for cluster analysis with dominant markers in maize (Zea mays L). Genetics and Molecular Biology, v.27, p.83-91, 2004.

NEVES, M.F.; VAL, A.M. do. Marcas em canais de distribuição: o caso da indústria de suco em laranja. Laranja, v.24, p.289-310, 2003.

NICOLOSI, E.; DENG, Z.N.; GENTILE, A.; LA MALFA, S.; CONTINELLA, G.; TRIBULATO, E. Citrus phylogeny and genetic origin of important species as investigated by molecular markers. Theoretical and Applied Genetics, v.100, p.1155-1166, 2000.

OLIVEIRA, A.C. Clorose variegada dos citros: quantificação molecular do agente causal, avaliação de trocas gasosas de plantas infectadas e mapeamento de lócus de resistência quantitativa de citros à Wells (1997) com fAFLPs. 2003. 281p. Tese (Doutorado) Universidade Estadual de Campinas, Campinas.

OLIVEIRA, A.C.; NOVELLI, V.M.; GARCIA, A.N.; CRISTOFANI, M.; MACHADO, M.A. Identification of citrus hybrids through the combination of a leaf apex morphology and SSR markers. Euphytica, v.128, p.397-403, 2002b.

OLIVEIRA, R.P. de; CRISTOFANI, M.; AGUILAR-VILDOSO, C.I.; MACHADO, M.A. Diversidade genética entre híbridos de tangerina 'Cravo' e laranja 'Pêra'. Pesquisa Agropecuária Brasileira, v.37, p.479-484, 2002a.

PEJIC, L.; AJMONE-MARSAN, P.; MORGANTE, M.; KOZUMPLICK, V.; CASTIGLIONI, P.; TARAMINO, G.; MOTTO, M. Comparative analysis of genetic similarity among maize inbred lines detected by RFLPs, RAPDs, SSRs, and AFLPs. Theoretical and Applied Genetics, v.97, p.1248-1255, 1998.

ROHLF, F.J. NTSYSpc: numerical taxonomy and multivariate analysis system. Setauket, NY: Exeter Software, 1997. 1 CD-ROM.

SALIBA-COLOMBANI, V.; CAUSSE, M.; GERVAIS, L.; PHILOUZE, J. Efficiency of RFLP, RAPD, and AFLP markers for the construction of an intraspecific map of the tomato genome. Genome, v.43, p.29-40, 2000.

SAMBROOK, J.; FRITSCH, E.E.; MANATIS, T. Molecular cloning: a laboratory manual. Cold Spring Harbor, NY: Cold Spring Harbor Laboratory Press, 1989. 3v.

SIMONE, M.D.; RUSSO, M.P.; PULEO, G.; MARSAN, P.A.; LORENZONI, C.; MAROCCO, A.; RECUPERO, G.R. Construction of genetic maps for Citrus aurantium and C. latipes based on AFLP, RAPD and RFLP markers. Fruits, v.53, p.383-390, 1998.

SNEATH, P.H.A.; SOKAL, R.R. Numerical taxonomy: the principles and practice of numerical classification. São Francisco: W. H. Freeman, 1973. 573p.

Recebido em 6 de abril de 2005 e aprovado em 2 de dezembro de 2005 